Document downloaded from:

http://hdl.handle.net/10251/172319

This paper must be cited as:

Morales-Gonzalez, M.; Arévalo-Alquichire, S.; Diaz, LE.; Sans-Tresserras, JȦ.; Vilariño, G.; Gómez-Tejedor, J.; Valero, MF. (2020). Hydrolytic stability and biocompatibility on smooth muscle cells of polyethylene glycol-polycaprolactone-based polyurethanes. Journal of Materials Research. 35(23-24):3276-3285. https://doi.org/10.1557/jmr.2020.303

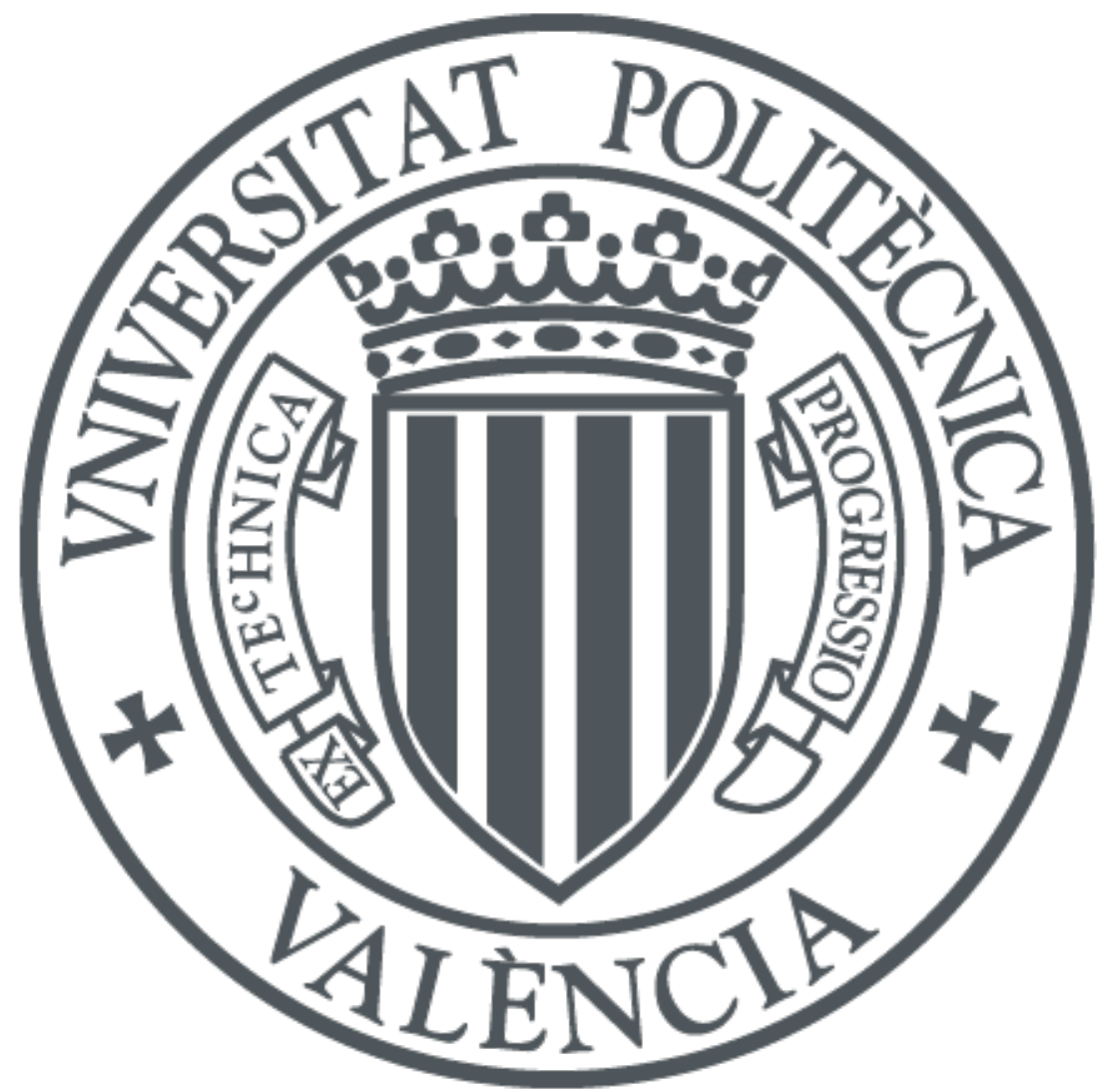

The final publication is available at

https://doi.org/10.1557/jmr.2020.303

Copyright Cambridge University Press (Materials Research Society)

Additional Information 


\title{
Hydrolytic stability and biocompatibility on smooth muscle cells of polyethylene-glycol-polycaprolactone-based polyurethanes
}

Maria Morales-Gonzalez, ${ }^{1,2}$ Said Arévalo-Alquichire, ${ }^{2}$ Luis E. Diaz, ${ }^{3}$ Juan Ángel Sans ${ }^{4}$

Guillermo Vilariño-Feltrer, ${ }^{5}$ José A. Gómez-Tejedor ${ }^{5,6}$ and Manuel F. Valero ${ }^{2, a}$

${ }^{1}$ Master in Process Design and Management, Faculty of Engineering, Universidad de La Sabana, Chía 140013, Colombia.

${ }^{2}$ Energy, Materials and Environment Group, Faculty of Engineering, Universidad de La Sabana, Chía 140013, Colombia.

${ }^{3}$ Bioprospecting Research Group, Faculty of Engineering, Universidad de La Sabana, Chía 140013, Colombia.

${ }^{4}$ Instituto de Diseño para la Fabricación y Producción Automatizada, MALTA Consolider, Universitat Politècnica de València, Valencia 46022, Spain.

${ }^{5}$ Centre for Biomaterials and Tissue Engineering, Universitat Politècnica de València, Valencia 46022, Spain.

${ }^{6}$ Biomedical Research Networking Centre in Bioengineering, Biomaterials and Nanomedicine (CIBER-BBN), Valencia 46022, Spain.

${ }^{a} A d d r e s s$ all correspondence to this author. e-mail: manuelvv@unisabana.edu.co

\begin{abstract}
Interactions between smooth muscle cells and biomaterials must not result in phenotype changes as this may generate uncontrolled multiplication processes and occlusions in vascular grafts. The aim of this study was to relate the hydrolytic stability and biocompatibility of polyurethanes on smooth muscle cells. A higher polycaprolactone (PCL) concentration was found to improve the hydrolytic stability of the material and the adhesion of smooth muscle cells. A material with 5\% polyethylene glycol, 90\% PCL, and 5\% pentaerythritol presented high cell viability and adhesion, suggesting a contractile phenotype in smooth muscle cells depending on the morphology.
\end{abstract}


Nevertheless, all polyurethanes retained their elastic modulus over 120 days, similar to the collagen of native arteries $(\sim 10 \mathrm{MPa})$. Furthermore, aortic smooth muscle cells did not present toxicity (viability over $80 \%$ ) and demonstrated adherence without any abnormal cell multiplication processes, which is ideal for the function to be fulfilled in situ in the vascular grafts.

\section{Introduction}

Typical therapies used for cardiovascular diseases involve the replacement of damaged or obstructed vessels with a vascular graft. Synthetic materials used clinically (polyethylene terephthalate and expanded polytetrafluoroethylene) tend to fail because of immune-mediated rejection by the host tissue and subsequent thrombosis ${ }^{1}$. In current approaches for the design and clinical implementation of tissue engineering vascular grafts (TEVGs), a conduit exhibiting the mechanical properties of blood vessel walls is sought, along with the incorporation of the graft into the vascular system by the formation of new tissues ${ }^{2}$.

Four key factors must be considered when designing a vascular graft: 1) the mechanical compatibility between the TEVG and the blood vessel wall; 2) the biodegradability processes that occur on the biomaterial (stability of the biomaterial); 3 ) the biocompatibility of the material with the host environment (endothelial cells, smooth muscle cells, and fibroblast) and the response of this environment to the material; and 4) the hemocompatibility of the material to prevent a foreign body reaction and thrombus formation ${ }^{1}$.

Assessing and adjusting the biodegradability rate is important in the design of vascular grafts such that different processes of new tissue formation are considered ${ }^{1}$. When no significant degradation occurs over long time periods, the immunological processes that may occur in the body permanently owing to the presence of a foreign body should be considered. In the human body, 
synthetic materials such as polyurethanes can undergo four degradation processes: those involving hydrolytic reactions with water in tissues; enzymatic reaction; chemicals oxidation owing to oxidants produced by tissues; and physical processes such as water swelling, load, and mechanical wear ${ }^{3}$. The mechanical stability is important as these degradation processes will determine the duration in which the material can maintain its functions and properties under the conditions of use $^{4}$.

With respect to the host environment, smooth muscle cells (SMCs) are essential for the success of vascular grafts as they are one of the components of the tunica media and are responsible of the mechanical behaviour at physiological conditions, specifically for the maintenance of the vascular tone and the resistance of blood vessels ${ }^{5,6}$. SMCs present two phenotypes: synthetic and contractile, which can be switched depending on the response of a certain mechanical stimulus. Their contractile phenotype can contract and relax the vessel ${ }^{1}$.

This study investigates two of the aforementioned key factors: biodegradation and biocompatibility over polyurethanes. The use of polyurethanes as synthetic materials has gained significant attention in the tissue engineering and design of vascular grafts, particularly in their production process, versatility, and biocompatibility ${ }^{3}$. Polyurethanes (PU) are a group of polymers that have become important in many biomedical applications as they are versatile and biocompatible materials owing to the innumerable possibilities of synthesis according to the characteristics of polyols and isocyanates. Such versatility is attributed to the presence of a segmented chemistry that allows the mechanical, physical and biological properties to be adjusted 7. To focus on the biocompatibility of materials, some investigations have been performed regarding the surface modification of PUs. This modification comprised the addition of hydroxyl 
groups with molecules such as polyethylene glycol (PEG) and sulfobetaine monomers, resulting in PUs with better biodegradability ${ }^{8}$. Attention on PEG in the design of biomaterials and vascular grafts has increased recently because of its ability to hydrate and the similarity it presents with extracellular matrices in terms of structure and physical and chemical properties ${ }^{9}$. Likewise, polycaprolactone (PCL) is a widely used polymer for biomedical applications owing to its biodegradability and high biocompatibility ${ }^{10,11}$.

Fabrication of PCL-PEG blends has shown an improvement in the cell response and have potential in a wide range of applications in tissue engineering (cardiovascular, nerve regeneration and bone tissue) and drug delivery, due to higher mechanical properties, better hemocompatibility and better cell compatibility with different cell lines. Peng et al. ${ }^{12}$ produced HMDI/PCL-PEG/DEG polyurethane hydrogels that showed good proliferation of fibroblast and would be useful for controlled release drug systems and tissue engineering scaffolds due to the improved hydrophilicity ${ }^{12}$. Likewise, some heterogeneous fibrous constructs derived from PCL/PEG blends can be promising for MC3T3-E1 cells adhesion, proliferation and spreading as well as for the increase of the tensile strength, Young's modulus and wettability of the membranes ${ }^{13}$. Also, Kupka et al. ${ }^{14}$ determined that the presence of PEG increased both the ability to absorb water and the rate of hydrolytic degradation, while PCL increased the cell viability human mesenchymal stem cells (MSCs) ${ }^{14}$. Other applications of PCL/PEG blends can be antibacterial vesicles for multifunctional drug carriers that are biocompatible and maintained the metabolic activities of L02 liver cells at various vesicle concentrations ${ }^{15}$; or scaffolds for tissue regeneration that possess highly surface area porous for cell attachment and were evaluated in a rat model after 20 weeks, showing proper mechanical properties, good processing ability, blood, cell and tissue compatibility and high nerve regenerated ability ${ }^{16}$. 
Hence, the aim of this study was to relate the hydrophilicity/hydrophobicity and hydrolytic stability of polyurethane and its biocompatibility with SMCs to obtain suitable biomaterials for the design of vascular grafts.

\section{Results and Discussion}

Polyurethanes were synthetised from blends of PEG, PCL and PE as crosslinking agent according to Table I and IPDI was used as NCO source.

Table I: Composition and contact angle of polyurethanes synthesised from polyethylene glycol (PEG), polycaprolactone (PCL), and pentaerythritol (PE). Results are presented as mean value $(n=50) \pm$ standard deviation. According to the individual Student's t-tests, means that do not share a letter are significantly different $(\mathrm{p}<0.05)$.

\section{Sample ID \\ PEG (\% w/w) PCL (\% w/w) PE (\% w/w) Contact angle $\left(^{\circ}\right)$}

\begin{tabular}{ccccc}
\hline PEG5\%-PCL90\%-PE5\% & 5 & 90 & 5 & $76.6 \pm 6.2^{\mathrm{a}}$ \\
PEG45\%-PCL45\%-PE10\% & 45 & 45 & 10 & $60.9 \pm 4.0^{\mathrm{b}}$ \\
PEG46.3\%-PCL46.3\%-PE7.5\% & 46.3 & 46.3 & 7.5 & $47.5 \pm 6.8^{\mathrm{c}}$ \\
PEG47.5\%-PCL47.5\%-PE5.0\% & 47.5 & 47.5 & 5 & $60.6 \pm 6.4^{\mathrm{b}}$ \\
\hline
\end{tabular}

The Raman spectra of the polyurethanes synthetised are shown in Figure 1. Distinctive peaks of the urethane bonds appeared at $1724(\mathrm{C}=\mathrm{O}), 1430-1450(\mathrm{~N}-\mathrm{H})$, and $1302 \mathrm{~cm}^{-1}(\mathrm{C}-\mathrm{N}){ }^{7}$. Furthermore, a peak at $2270 \mathrm{~cm}^{-1}$ corresponding to the isocyanate group was absent, suggesting the complete reaction for urethane bond formation ${ }^{17}$. 


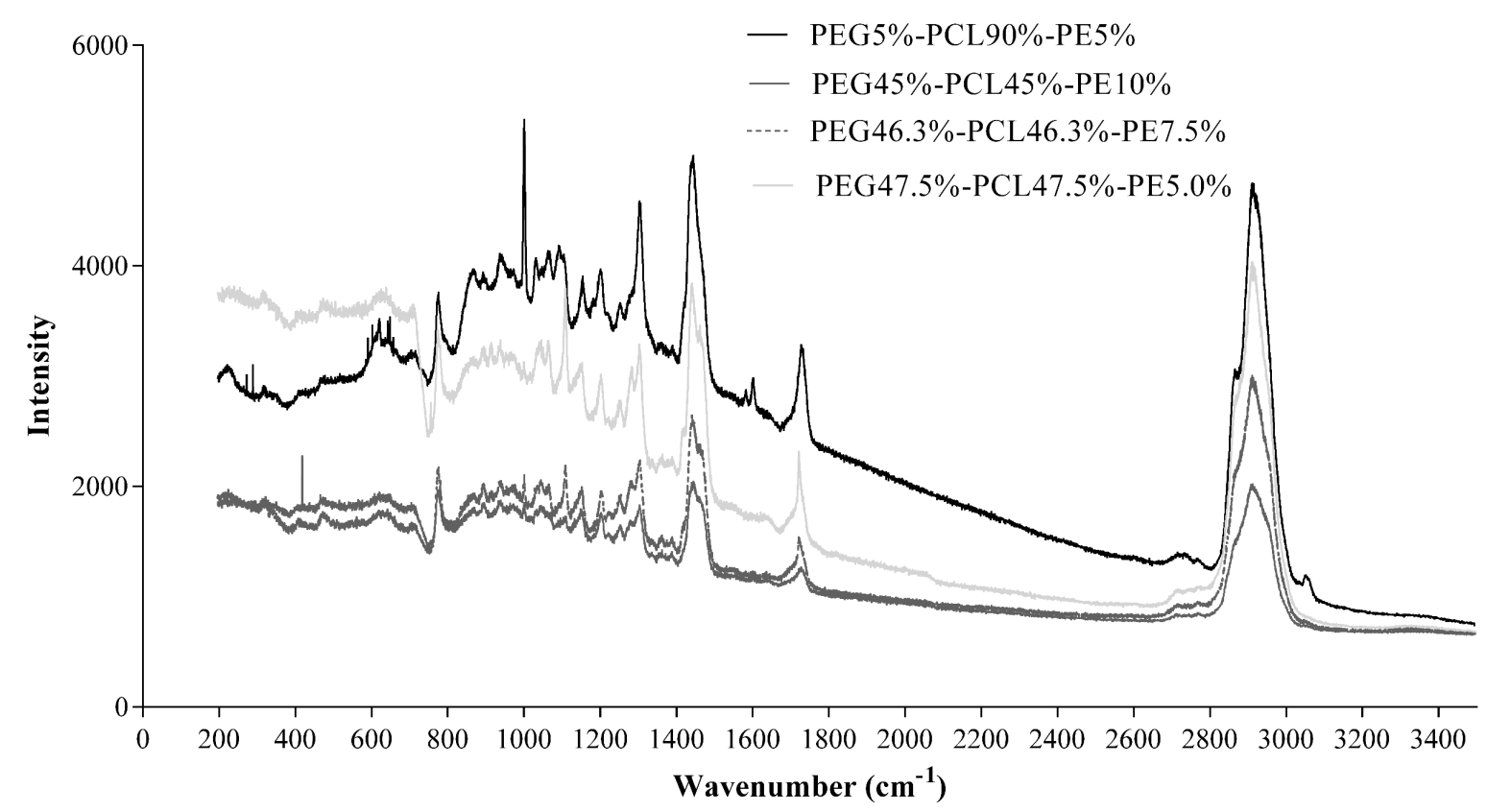

Figure 1: Raman spectrum of polyurethanes synthesised from polyethylene glycol (PEG), polycaprolactone (PCL), pentaerythritol (PE), and isophorone diisocyanate (IPDI).

The region between 850 and $1111 \mathrm{~cm}^{-1}$ can be assigned to the skeleton of PCL; some authors attribute those peaks to interactions of $\mathrm{C}-\mathrm{C}$ stretch, $\mathrm{C}-\mathrm{O}$ stretch, and $\mathrm{C}-\mathrm{COO}$ stretch, which are characteristic of polyesters ${ }^{18,19}$. Raman bands at $2900-2920$ and $2700 \mathrm{~cm}^{-1}$ can be attributed to the asymmetric and symmetric $\mathrm{CH}$ stretching vibrations of $\mathrm{CH}_{2}$ groups, respectively ${ }^{7,18,20}$.

A narrower band of the peak at $1725 \mathrm{~cm}^{-1}$ suggests more crystalline domains in PCL; likewise, the change in the intensity of the Raman spectra suggests a more crystalline structure for polyurethane PEG5\%-PCL90\%-PE5\% ${ }^{20}$. That crystallinity decreased with the amount of PCL in the polyurethane owing to the semi-crystalline nature of PCL as well as the amount of PEG and crosslinking agent used. This information complements the previous investigation of the research group ${ }^{21}$, in which it was observed that at a lower average molecular weight of polyols, the 
crystallinity of the biomaterial may decrease at low temperatures and a decrease in the crosslinking agent will decrease the PEG/PCL/PE polyurethane phase mixing ${ }^{21}$.

Also, the peak of the carbonyl stretching wavenumbers at 1700 and $1712 \mathrm{~cm}^{-1}$ may correspond to $\mathrm{H}$-bonded $\mathrm{C}=\mathrm{O}$ from urethane linkages ${ }^{22}$. A decrease in the intensity of this peak is observed with the increase of PE content (Figure 1). The decrease of the bonded carbonyl by the chemical crosslinking with PE of polyurethanes reduced the hydrogen bonding and thus reduces the hard segments interactions, decreasing the phase separation ${ }^{23}$, as mention above. Likewise, Chung et al. ${ }^{22}$ observed that the chemical cross-linking by pentaerythritol (a four-way crosslinker) changed the polymer chain alignment by reduction of the interaction between chains ${ }^{23}$.

In tissue engineering, the knowledge regarding the interactions between the surfaces of biomaterials and cells is necessary; it has been shown that the hydrophobicity and hydrophilicity of a polymer surface (wettability) is one of the important factors affecting these interactions ${ }^{24}$.

The contact angle values of the surface of polyurethanes are presented in Table I. A contact angle over $90^{\circ}$ represent an unfavourable wetting of the surfaces and suggest more hydrophobic surfaces 25; therefore, polyurethanes present a hydrophilic surface. However, polyurethanes with high amount of PCL (PEG5\%-PCL90\%-PE5\%) showed a less hydrophilic behaviour. The presence of PCL increased the contact angle owing to its hydrophobicity ${ }^{26}$. 


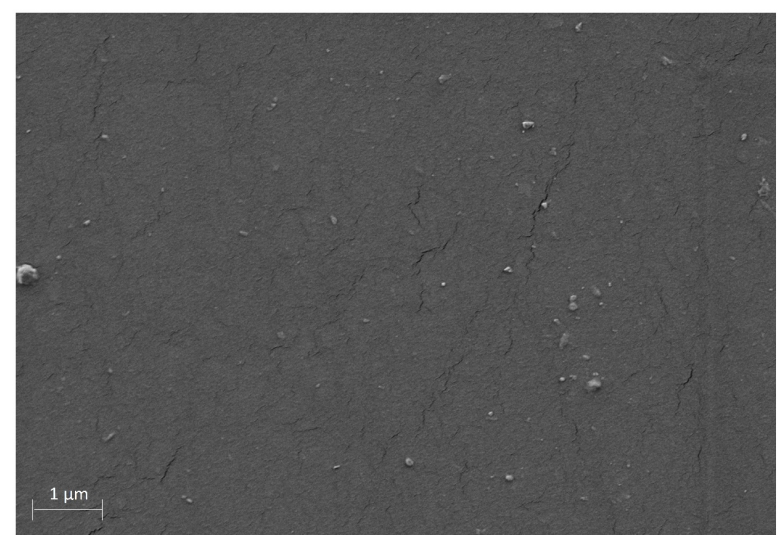

(a)

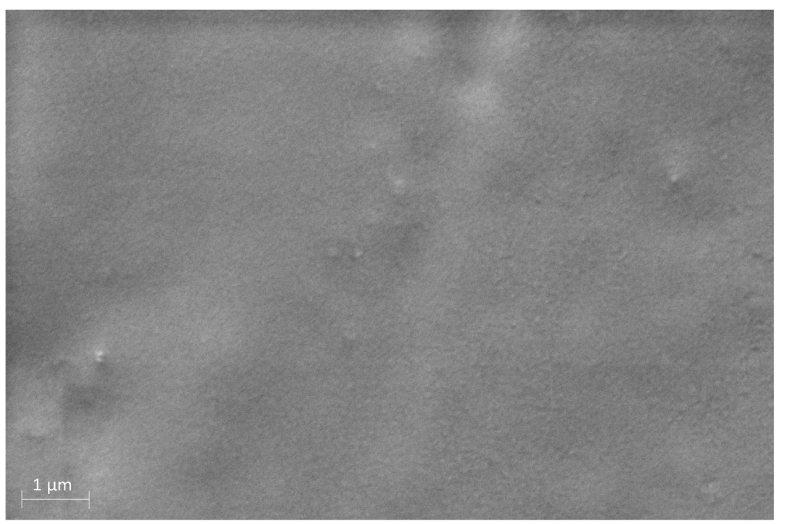

(c)

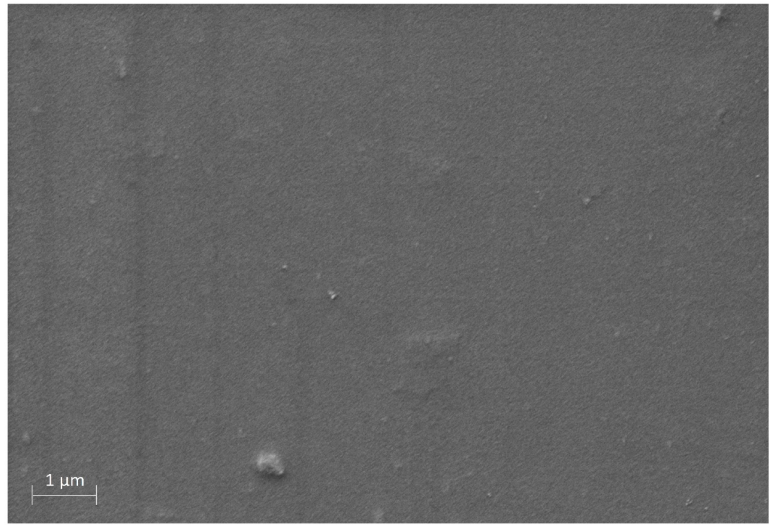

(b)

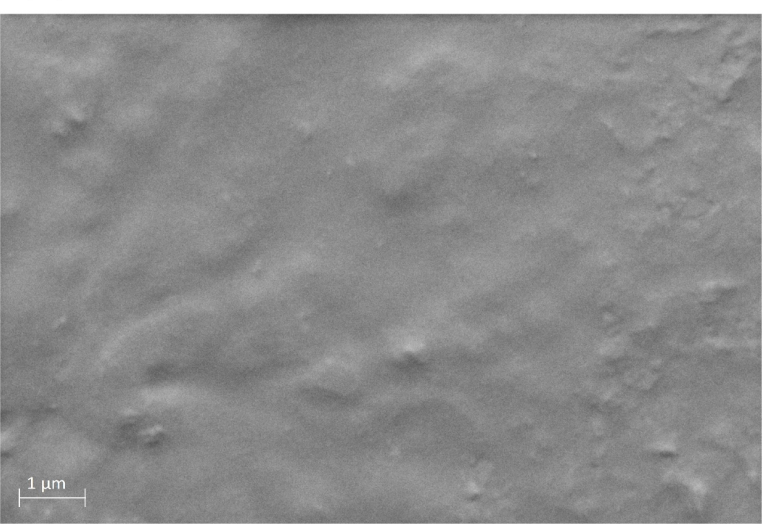

(d)

Figure 2: FESEM micrographs at $10000 \times$, of polyurethanes synthesised from polyethylene glycol (PEG), polycaprolactone (PCL), pentaerythritol (PE), and isophorone diisocyanate (IPDI): (a) PEG5\%-PCL90\%-PE5\%, (b) PEG45\%-PCL45\%-PE10\%, (c) PEG46.3\%-PCL46.3\%-PE7.5\% and (d) PEG47.5\%-PCL47.5\%-PE5.0\%.

To know the microstructure of the different materials, FESEM micrographs were recorded and differences on surfaces were observed related to the change of the concentration of PCL and PEG (Figure 2). The materials show a more irregular surface with increased PCL and decrease concentration of PE owned by the polyurethane phase mixing. Smoother surfaces can be observed in materials with higher concentration of the crosslink agent (PE) (Figure 2b) as well as higher PEG content (Figure 2c); these results correlated with the hydrophilicity of each polyurethane as well as the cell adhesion. 

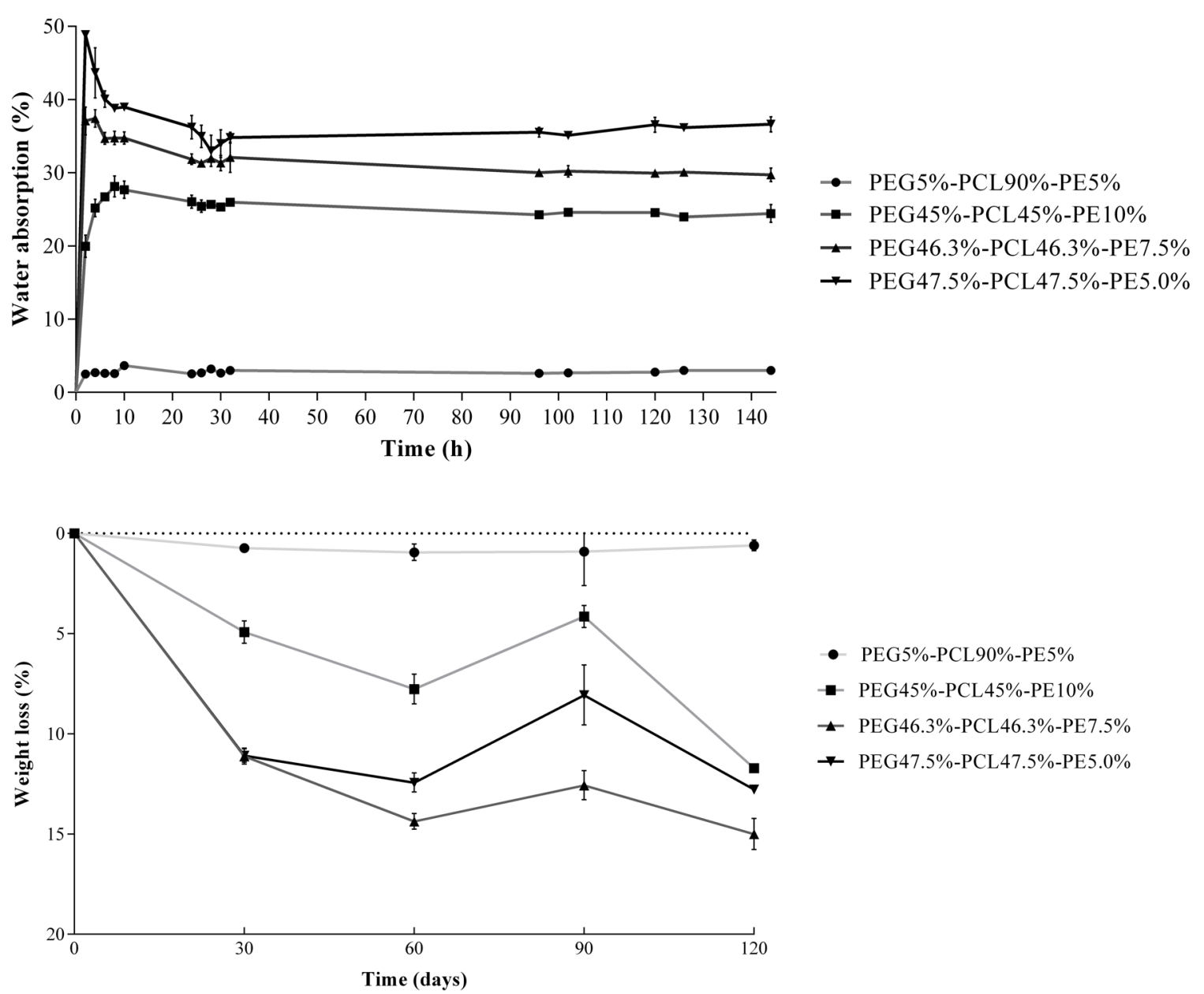

(b)

Figure 3: (a) Water absorption (\%) over $144 \mathrm{~h}$ and (b) weight loss (\%) over 120 days in phosphate buffer saline

(PBS) $(\mathrm{pH}=7.4)$ of polyurethanes synthesised from polyethylene glycol (PEG), polycaprolactone (PCL), pentaerythritol (PE), and isophorone diisocyanate (IPDI). Mean value ( $n=3) \pm$ standard deviation.

Hence, changes in the hydrophobicity/hydrophilicity of polyurethanes can be explained by both the hydrophobicity of PCL and hydrophilicity of PEG. Additionally, the aggregation of PEG in the polyurethane mixture increased the swelling of the material owing to its hydrophilicity and its ability to establish hydrogen bonding with water molecules ${ }^{26,27}$. Contact angle $<90^{\circ}$ indicates a favourable surface wetting ${ }^{25}$ and hence a favourable water absorption in polyurethane. The water absorption increased with the concentration of PEG, i.e., from $2 \%$ in polyurethane with $5 \%$ of PEG 
to $48 \%$ in polyurethane with $47.5 \%$ of PEG (Figure $3 a$ ). The water uptake of the polyurethanes occurred in a short time period before $10 \mathrm{~h}$, after which they reached equilibrium.

Furthermore, with the increase in water absorption, the initial hydrolysis of the material was facilitated ${ }^{3}$.The percentage of weight loss of polyurethanes are shown in Figure $3 \mathrm{~b}$. For the PEG5\%-PCL90\%-PE5\% polyurethane, the weight loss (2\%) over the $120 \mathrm{~d}$ remained constant; this can be attributed to the presence of PCL and its hydrophobicity, which allowed the hydrolytic stability of the final biomaterials to be controlled ${ }^{3}$. By contrast, with the addition of PEG in the backbone of the biomaterials, the hydrolytic degradation increased; therefore, polyurethanes with high amounts of PEG reached a 15\% weight loss over $120 \mathrm{~d}$ (4 months).

Hou et al. produced poly(ester-urethane)s with different PCL amounts; for polyurethanes with high PCL contents (100\%), the weight loss reached $46 \%$, the tensile properties were lost, and fragmentation occurred after $160 \mathrm{~d}$ of degradation ${ }^{28}$. Even though the ether component was more resistant to hydrolytic degradation than the polyesters ${ }^{3}$, the crosslinking process of polyurethane resulted in more hydrogen bonds between the urethane groups and between urethane and ester groups of PCL, which generated a compact network ${ }^{27}$ with a higher hydrophobicity and slower degradation rates. Based on the results, the hydrophilicity of PEG contributed significantly to the degradation of polyurethanes, as the ester groups of the material were exposed, allowing it to interact with the water molecules and resulting in chain scission ${ }^{28}$. Furthermore, the crosslinking process contributed significantly to the biostability of polyurethanes. 


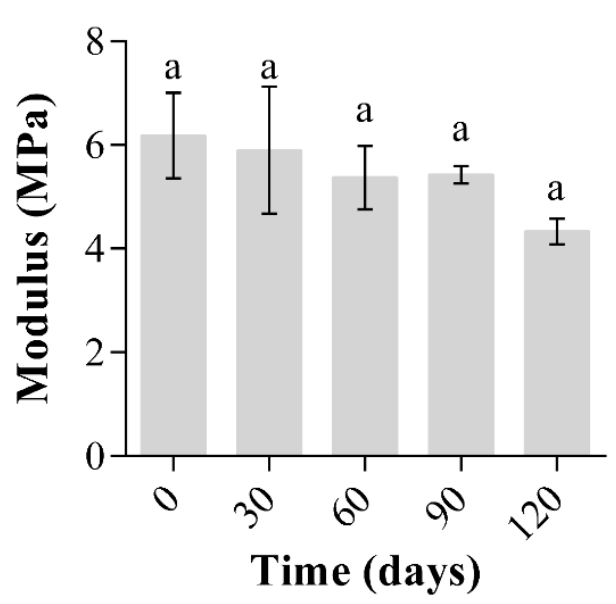

(a)

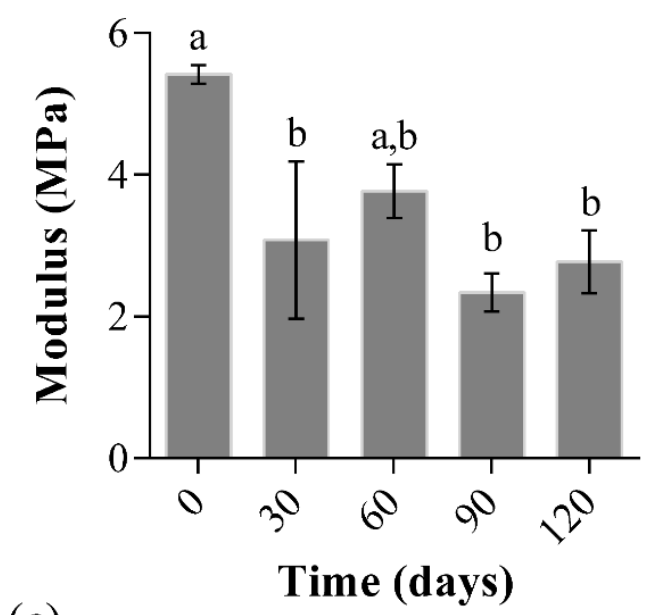

(c)

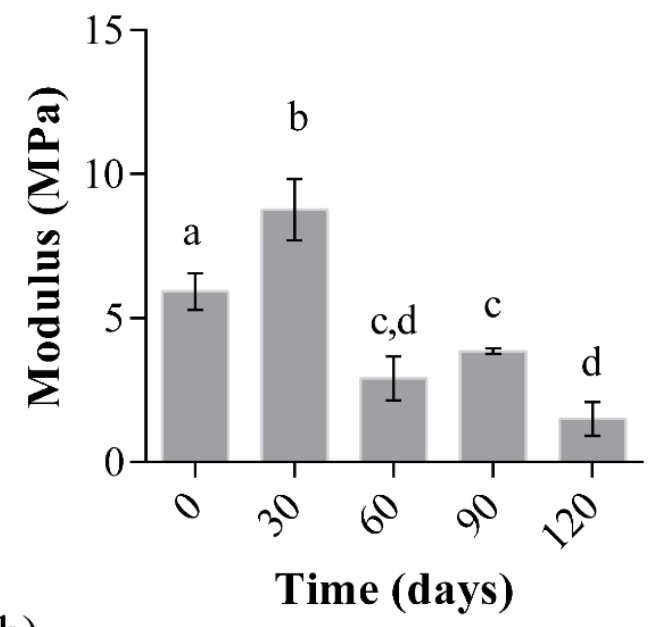

(b)

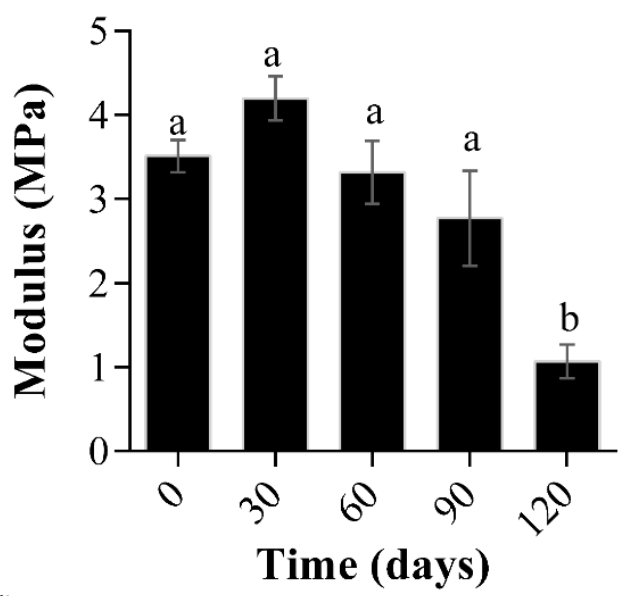

(d)

Figure 4: Elastic modulus over $120 \mathrm{~d}$ of polyurethanes synthesised from polyethylene glycol (PEG),

polycaprolactone (PCL), pentaerythritol (PE), and isophorone diisocyanate (IPDI): (a) PEG5\%-PCL90\%-PE5\%, (b) PEG45\%-PCL45\%-PE10\%, (c) PEG46.3\%-PCL46.3\%-PE7.5\% and (d) PEG47.5\%-PCL47.5\%-PE5.0\%. Mean value $(n=3) \pm$ standard deviation. According to the analyses of variances and Tukey pairwise comparisons, means that do not share a letter are significantly different $(\mathrm{p}<0.05)$.

Figure 4 shows the elastic modulus of each film calculated at every four weeks of the degradation process. As shown, the elastic modulus of polyurethane PEG5\%-PCL90\%-PE5\% remained stable 
for over 120 d (no significance difference). Furthermore, polyurethanes PEG46.3\%-PCL46.3\%PE7.5\% and PEG47.5\%-PCL47.5\%-PE5.0\% presented a decrease in the elastic modulus after 60 and $90 \mathrm{~d}$, respectively. The decrease in elastic modulus for polyurethane PEG46.3\%-PCL46.3\%PE7.5\% was approximately $38.2 \%$ (Figure 4c), which is consistent with the weight loss experienced. Nevertheless, this material is suitable for vascular graft applications and smalldiameter vascular substitutes in which the expected range of the elastic modulus is between 0.01 and $100 \mathrm{MPa}^{29}$. As reported by Liu et al. ${ }^{27}$, the surface grafting of hydrophilic PEG on aliphatic PCL-PEUs resulted in a material that can maintain its mechanical properties for more than six months with a weight loss of $25 \%$ after 18 months. This biostability in terms of weight loss and elastic modulus is an important property and requirement for long-term implant biomaterials, and the polyurethanes prepared in this study yielded an elastic modulus comparable to the range of the components of the human coronary artery wall (10-100 MPa for collagen).

Additionally, the leachates that may be generated in the hydrolytic degradation processes of the polyurethanes after a $30 \mathrm{~d}$ incubation were nontoxic to the aortic SMC and indicated cell viabilities exceeding 90\% (Figure 5). 


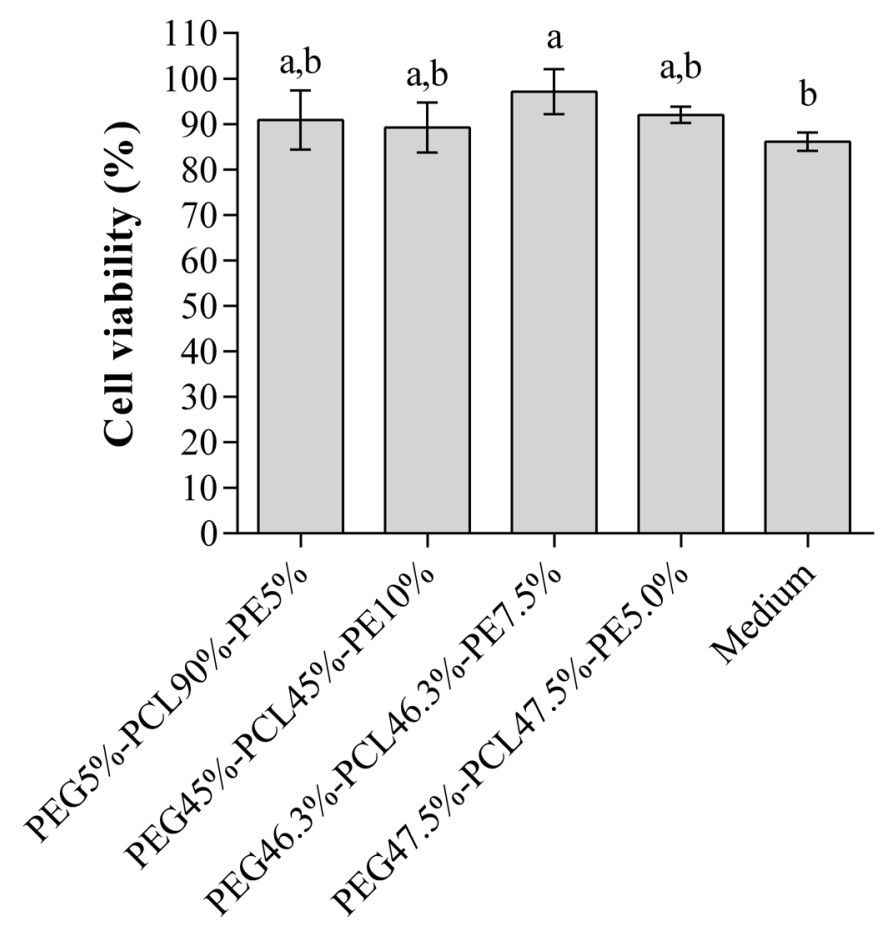

Figure 5: Smooth muscle cell viability after in contact for $24 \mathrm{~h}$ with $30 \mathrm{~d}$ polyurethane leachates. Mean $(\mathrm{n}=3) \pm$ standard deviation. According to the analyses of variances and Tukey pairwise comparisons, means that do not share a letter are significantly different $(\mathrm{p}<0.05)$

For most animal cells, a moderate hydrophilicity is preferred for growth and adhesion ${ }^{24}$. The introduction of a PCL and PEG blend in the composition of polyurethane yields moderate hydrophobic surfaces, which are a better environment for human aortic SMC viability and adhesion. The results presented in Figure 6 show that the SMCs were metabolically active, and that the polyurethanes had low cytotoxic effects on the SMCs. All materials showed cell viability exceeding $80 \%$. Even though the greatest viability (95\%) was observed in polyurethanes PEG5\%PCL90\%-PE5\% and PEG45\%-PCL45\%-PE10\%, no significant difference was observed in the viability of SMCs in the synthesised polyurethanes. 


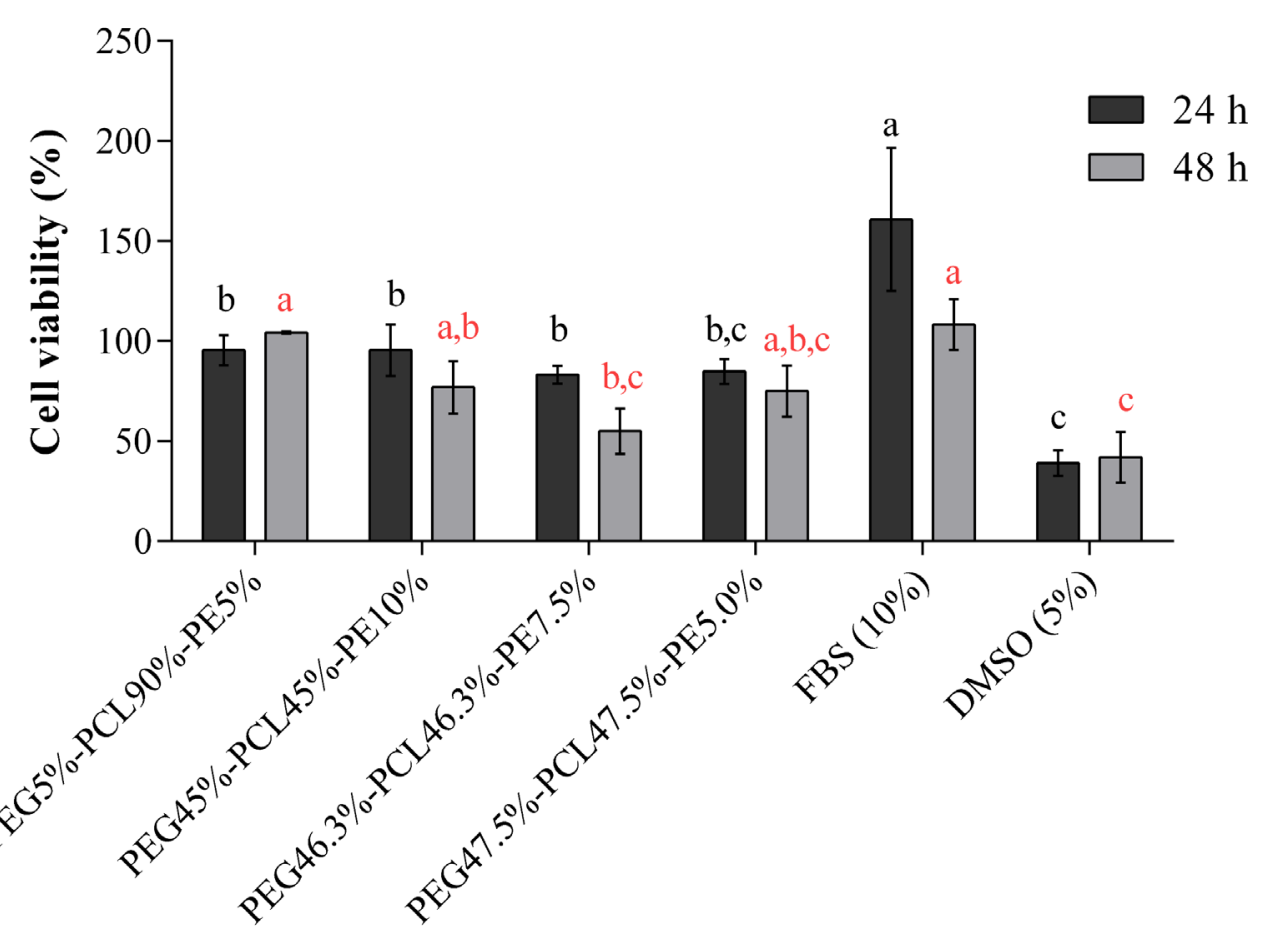

Figure 6: Smooth muscle cell viability after $24 \mathrm{~h}$ and $48 \mathrm{~h}$ on polyurethanes synthesised from polyethylene glycol (PEG), polycaprolactone (PCL), pentaerythritol (PE) and isophorone diisocyanate (IPDI). Mean ( $\mathrm{n}=3) \pm$ standard deviation. According to the analyses of variances and Tukey pairwise comparisons, means that do not share a letter are significantly different $(\mathrm{p}<0.05)$.

For SMC proliferation, polyurethanes with mixtures of PEG and PCL enhanced cell proliferation in the first $24 \mathrm{~h}$; however, at $48 \mathrm{~h}$, SMC proliferation was limited in the biomaterials (cell viability remains constant after $48 \mathrm{~h}$ ). With the presence of fetal bovine serum (FBS), the SMC viability increased in 24 and $48 \mathrm{~h}$, whereas with dimethyl sulfoxide (DMSO), the viability decreased (Figure 6). Therefore, the materials did not seem to generate uncontrolled proliferation in the SMCs. The decrease in the proliferation of SMCs contributed significantly to the understanding of the phenotypic change occurring in the cells and the patency of the vascular graft. The abnormal proliferation of SMCs owing to a phenotype change from contractile to synthetic ${ }^{30,31}$ resulted in a migration and an accumulation from the media into the intima ${ }^{5}$ and is an early event in intimal hyperplasia. Contractile phenotypes can minimise the compliance mismatch ${ }^{6}$, as they are 
responsible for the regulation of vascular tone and blood pressure through the contraction and relaxation of blood vessels ${ }^{32}$.

(a)
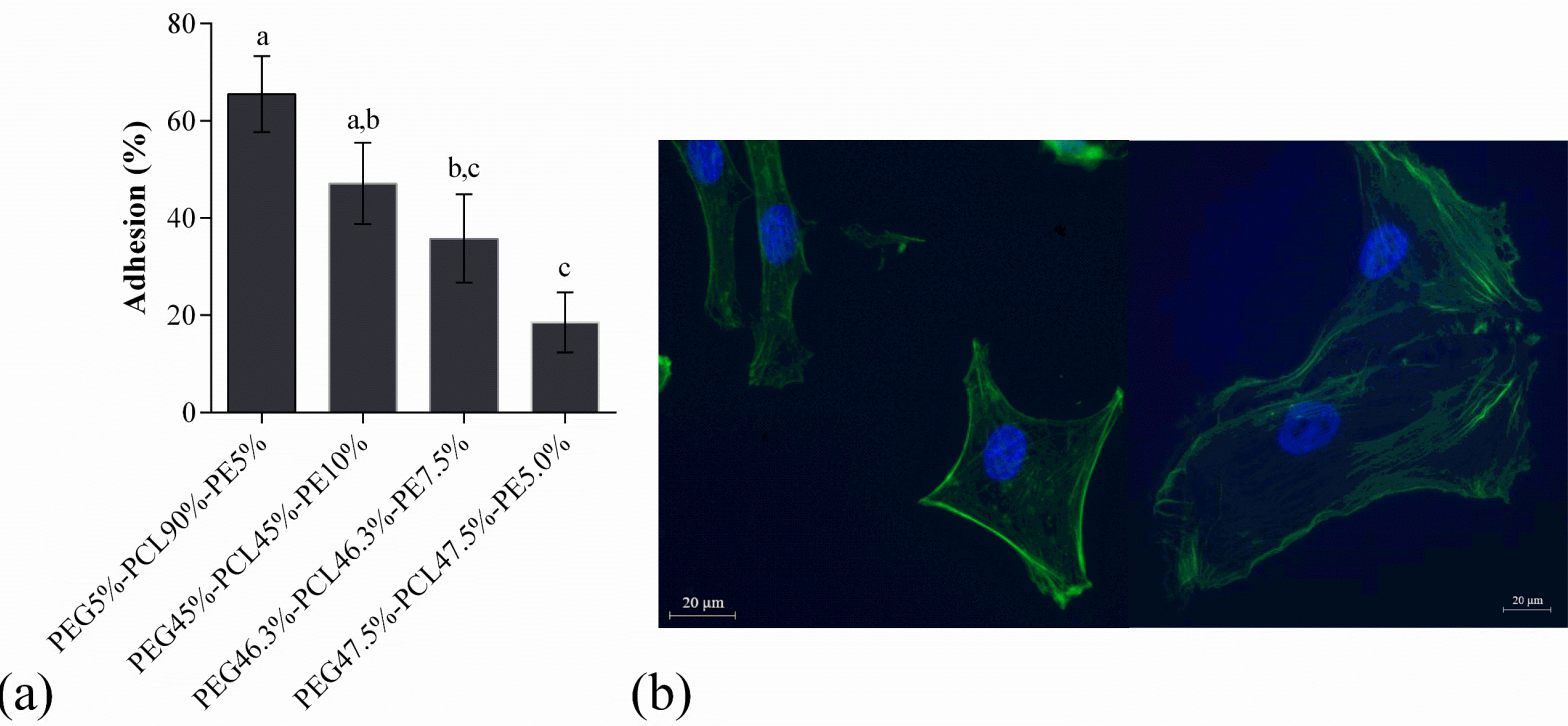

(b)

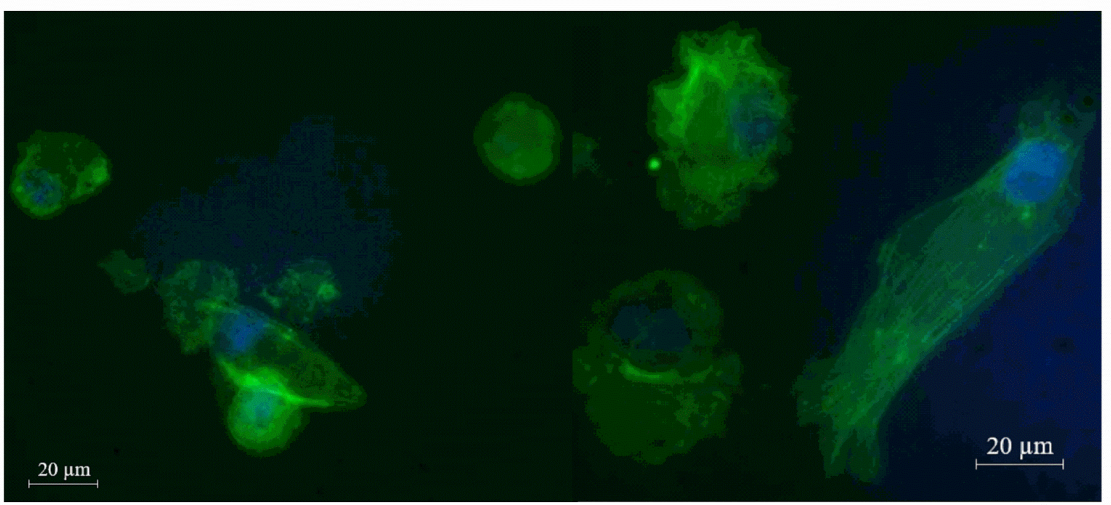

(c)

Figure 7: (a) Smooth muscle cell adhesion after $3 \mathrm{~h}$ on polyurethanes synthesised from polyethylene glycol (PEG), polycaprolactone (PCL), pentaerythritol $(\mathrm{PE})$ and isophorone diisocyanate (IPDI). Mean $(\mathrm{n}=3) \pm$ standard deviation. According to the analyses of variances and Tukey pairwise comparisons, means that do not share a letter are significantly different $(\mathrm{p}<0.05)$ and optical microscopy images $(60 \mathrm{X})$ of phalloidin (green) and DAPI (blue) staining of smooth muscle cells (SMCs) on polyurethanes (b) PEG5\%-PCL90\%-PE5\% and (c) PEG46.3\%PCL46.3\%-PE7.5\%.

(a) Hemolysis (\%) and (b) platelet adhesion (\%) to polyurethanes synthesised from PEG, PCL, PE and IPDI. Mean value $(n=3) \pm$ standard deviation. According to the analyses of variances and Tukey pairwise comparisons, means that do not share a letter are significantly different $(\mathrm{p}<0.05)$ 
Likewise, polyurethanes with a high amount of PCL (PEG5\%-PCL90\%-PE5\%) indicated the greatest adhesion of SMCs (Figure 7a). A reduction in the amount of PCL reduced the SMC adhesion. On polyurethane PEG5\%-PCL90\%-PE5\%, SMCs presented both an elongated and a rhomboid cell morphology (Figure 7b), suggesting that the cells were in different points of differentiation between the two phenotypes of the cells (contractile and synthetic) ${ }^{6}$.

Once the biomaterial is immersed in the cellular environment, the adsorption of proteins on the surface of the material can enable cell adhesion to the cell through the production of signals to cell adhesion receptors ${ }^{33}$. The attached cells can generate and secrete an extracellular matrix that allows cell proliferation and differentiation. Polyurethane PEG46.3\%-PCL46.3\%-PE7.5\% presented a low cell adhesion and the attached cells exhibited a more rounded morphology (Figure 7c), suggesting that this substrate did not promote a good environment for adhesion, extension, and appropriate functions, and that in a longer contact time, cell death processes can be promoted. Owing to this poor adhesion, proliferation decreased after $48 \mathrm{~h}$ (Figure 6). These results suggest that changes in the composition of polyurethanes resulted in changes in the cell structure, which can induce a change in the phenotype of the SMCs.

According to the literature, the presence of PEG causes a decrease in the adhesion of cells owing to a decrease in protein adsorption ${ }^{9}$. Nevertheless, the use of PEG in the design of biomaterials improves the wettability and anti-thrombotic properties ${ }^{9}$. Guan et al. generated PCL-PEG-PCL triblock copolymers with hydrophilic surfaces and evaluated their adhesion on human endothelial cells. For these materials, adhesion was favoured with the increasing hydrophobicity of the surfaces, with an increase in the length of PCL and a decrease in PEG in the soft segment. They attributed this behaviour to the increase in the adsorption of serum adhesion proteins in the hydrophobic surfaces ${ }^{34}$. 
Likewise, Kupka et al. ${ }^{14}$ synthesised PU films with variable PCL/PEG diol ratios and 1,6diisocyanatohexane; they observed that the water absorption and hydrolytic degradation of the materials as well as the adhesion of human mesenchymal stem cells were related to the amount of hydrophilic PEG in the PU composition. PU films with an increased amount of PEG presented the highest water absorption and hydrolytic degradation, whereas the cell adhesion was poor because of the non-adherent environment for cells that did not adhere to or detach from the PU surface ${ }^{14,35}$. All these evidences are consistent with the present investigation, in which SMC adhesion is favoured in the material with a greater PCL content.

The synthesis of PCL-PEG blends improved the cell response by overcoming the hydrophobicity of PCL and hydrophilicity of PEG. Different studies reported cell attachment, proliferation, and ECM production on bone-marrow-derived stromal cell lines ${ }^{36}$, rabbit SMCS ${ }^{37}$, and on osteoblasts $(\mathrm{MC} 3 \mathrm{~T} 3-\mathrm{E} 1)^{13}$.

Therefore, for the design and fabrication of vascular grafts, it is important to understand the response and behaviour of the cells that compose a blood vessel that will be in contact with the device such that the latter functions correctly and appropriately in the human body. Understanding the mechanobiology of the cells that compose the vessel walls can result in new and better vascular grafts applicable to cardiovascular disease treatment.

Changes occur in the properties and subsequent functions of the polyurethanes even when changes in their composition are minimal. For hydrolytic stability, the characteristics of polyols and the amount of crosslinking agent used are significant factors. A change in composition results in a change in the contact angle, which consequently results in differences in water absorption and hydrolytic degradation. Furthermore, those surfaces will determine the interactions with SMCs 
mainly in terms of morphology and phenotype, which will determine their adhesion and proliferation.

The addition of more hydrophobic polyols such as PCL results in more hydrolytically stable materials (low weight loss and preservation of mechanical properties); however, the presence of hydrophilic polyols such as PEG facilitates the absorption of water, thereby creating better environments for the adaptation of SMCs that allow their mechanobiology to be controlled such that uncontrolled proliferation processes and occlusion of blood vessels can be avoided, as in the case of polyurethane PEG5\%-PCL90\%-PE5\%.

\section{Conclusions}

The composition of a material affects its hydrophilicity. In this study, the characteristics of polyols (PEG and PCL are hydrophilic and hydrophobic polyols, respectively) determined the behaviour of the material and subsequently their biocompatibility with SMCs. An increase in the PCL content on polyurethanes may result in an increase in the crystallinity owing to the amount of intermolecular forces, thereby resulting in the hydrolytic stability of polyurethanes in terms of their weight loss and elastic modulus. Morphology and proliferation results suggested the contractile phenotype of SMCs after $48 \mathrm{~h}$ surface-cell interactions, which were related to the hydrophobicity of the surface and the wettability of polyurethane. Moderate hydrophobic surfaces were a better environment for human aortic SMC viability and adhesion without abnormal cell multiplication processes; hence, polyethylene-glycol-PCL polyurethanes are potential candidates for cardiovascular applications. 


\section{Materials and Methods}

PCL diol with an average molecular weight of Mn 2000, isophorone diisocyanate (IPDI), and N,N-dimethylformamide (DMF) were purchased from Sigma-Aldrich (St. Louis, MO, USA). Polyethylene glycol (PEG, Mn 1000) was purchased from Merck KGaA (Darmstadt, Germany), and pentaerythritol (PE) from Alfa Aesar (Heysham, UK). Phosphate buffer saline (PBS) was purchased from VWR (Radnor, PA, USA). Resazurin solution (Gibco, Thermo Fisher, USA). Aortic smooth muscle cells (AoSMCs) and basal smooth muscle cell medium (SmBM) supplemented with a single medium SMC growth medium kit (SmGM-2) (5\% FBS, 0.1\% insulin , $0.2 \%$ human fibroblast growth factor-B (hFGF-B), $0.1 \%$ gentamicin $\mathrm{A}, 0.1 \%$ hEGF) were purchased from Lonza (Walkersville, Maryland).

\section{Polyurethane synthesis}

Polyurethanes were synthetised via a two-step polymerisation ${ }^{21}$. PCL and PEG were used as polyols, isophorone diisocyanate as an NCO source, and pentaerythritol as a crosslinker. Each polyol sample (Table I) was diluted in $10 \mathrm{~mL}$ of DMF at $70{ }^{\circ} \mathrm{C}$; subsequently, IPDI was added at a $\mathrm{NCO} / \mathrm{OH}$ ratio of 1 and allowed to react for $15 \mathrm{~min}$ at $70{ }^{\circ} \mathrm{C}$ and $200 \mathrm{rpm}$. Pentaerythritol was diluted in $10 \mathrm{~mL}$ of DMF at $110{ }^{\circ} \mathrm{C}$ and $200 \mathrm{rpm}$ and added to the prepolymer. Solvent evaporation was allowed. Thin films of $150 \mu \mathrm{m}$ were prepared in glass plates with an Elcometer 3580 Casting Knife Film Applicator (Elcometer Ltd., Manchester, UK) and cured at $110{ }^{\circ} \mathrm{C}$ for $12 \mathrm{~h}$. Subsequently, the samples were immersed in water for $6 \mathrm{~h}$, washed with distilled water, and removed mechanically from the glass plates. The polyurethanes were denoted according to the polyol-crosslinking composition: PEG\%-PCL\%-PE\%. The blends for this investigation were selected based on previous studies regarding on the phase mixing of polyurethanes ${ }^{21}$ (Table I). 


\section{Physico-chemical characterisation}

\section{Raman spectroscopy}

Raman spectra were recorded in the range of 200 to $3500 \mathrm{~cm}^{-1}$ using a Jobin-Yvon LabRam spectrometer (HORIBA, France) combined with a thermoelectrically cooled multichannel CCD detector with a spectral resolution better than $2 \mathrm{~cm}^{-1}$. The spectrometer contained a 1200 trace $/ \mathrm{mm}$ diffraction grating with a volume Bragg grating filter and excitation was performed with a red He: Ne laser (wavelength: $632.8 \mathrm{~nm}$ ).

\section{Water contact angle}

The hydrophilicity of polyurethane was measured using the sessile drop method in an OCA20 device (Data Physics, Filderstadt, Germany); a $5 \mu \mathrm{L}$ drop of deionised water at $23{ }^{\circ} \mathrm{C}$ was used. At least 50 measurements per polymer in different areas were obtained, and the average of those measurements was reported ${ }^{7}$.

\section{Field Emission Scanning Electron Microscopy (FESEM)}

According to Uscátegui et al. ${ }^{38}$ morphological characterization of materials was performed with a field-emission scanning electron microscope (FESEM, ZEISS ULTRA 55 from Oxford Instruments, Abingdon, UK). The samples were coated with platinum with an accelerating voltage of $1.5 \mathrm{kV}$ and a magnification of $10000 \mathrm{x}$.

\section{Water absorption}

Samples disks ( $8 \mathrm{~mm}$ diameter) were immersed in $1.5 \mathrm{~mL}$ of distilled water and incubated for 144 h at $37^{\circ} \mathrm{C}^{7}$. Water absorption was calculated after $1,2,3,4,6,8,10,24,26,28,30,32,96,102$, 120, 126 and $144 \mathrm{~h}$ using Equation 1, where $W_{o}$ is the initial weight and $W_{s}$ the final weight. 


$$
\% \text { water absortion }=\frac{W_{s}-W_{o}}{W_{o}} \times 100
$$

\section{Hydrolytic degradation}

The degradation was evaluated in terms of weight and mechanical property losses as described below. Hydrolytic degradation was performed in PBS (137 mM NaCl, $10 \mathrm{mM}$ Phosphate, $2.7 \mathrm{mM}$ $\mathrm{KCl})$ at $\mathrm{pH}$ 7.4. Specimens between 10 and $50 \mathrm{mg}$ measuring $15 \mathrm{~mm} \times 3.5 \mathrm{~mm}$ (length $\times$ width) were immersed in $1.5 \mathrm{~mL}$ of PBS for $120 \mathrm{~d}$ at $37^{\circ} \mathrm{C}$. After every $30 \mathrm{~d}$ (four weeks), the samples were washed with distilled water and dried in a vacuum chamber for $24 \mathrm{~h}$; subsequently, the weight was recorded, and mechanical testing was performed. The weight loss was calculated using Equation 2, where $W_{s}$ and $W_{o}$ correspond to the dry weight at each time and the initial weight, respectively.

$$
\% \text { weight loss }=\frac{W_{S}-W_{o}}{W_{o}} \times 100
$$

A mechanical analysis was performed in a TMA/SS6000 dilatometer (Seiko Instruments, Chiba, Japan) to elongate the degraded samples at a rate of $100 \mathrm{mN} / \mathrm{min}$ up to $5884 \mathrm{mN}$ and $20^{\circ} \mathrm{C}$. The force and height variation values were normalised by dividing these values by the area and initial height, respectively to obtain the stress-strain curve to calculate the elastic modulus.

\section{In vitro biocompatibility tests}

AoSMCs were cultured in SmBM supplemented with SmGM-2. The medium was changed daily, allowing the cells to reach confluence. The cells were used between passages 5 and 6 . Before each 
test, the polyurethanes were sterilised by ultraviolet light for $30 \mathrm{~min}$ on each side and incubated in distilled water for $24 \mathrm{~h}$.

\section{Cell viability and proliferation}

Polyurethanes were placed on individual wells of 96-well plates, and a cell suspension (100 $\mu \mathrm{L})$ with a density of $4 \times 10^{5}$ cell $/ \mathrm{mL}$ was seeded and cultured in contact with the polyurethane samples for 24 and $48 \mathrm{~h}$ with $5 \% \mathrm{CO}_{2}$ at $37{ }^{\circ} \mathrm{C}^{39}$. At each time point, $50 \mu \mathrm{L}$ of resazurin solution $(44 \mu \mathrm{M})$ was added and incubated for $4 \mathrm{~h}$ at $37^{\circ} \mathrm{C}$. The fluorescent product resorufin was measured at a wavelength of $590 \mathrm{~nm}$ with an excitation wavelength of $560 \mathrm{~nm}$ using a Varioskan ${ }^{\mathrm{TM}}$ LUX multimode microplate reader (Thermo Scientific ${ }^{\mathrm{TM}}$, Thermo Fisher, USA). Cell-free polyurethanes were used as blanks. For positive controls, wells with cells and 10\% FBS were used, while wells with cells containing 5\% DMSO were used as negative controls. Cell viability is expressed in percentage according to Equation 3, where UF is the units of fluorescence.

$$
\% \text { cell viability }=\frac{U F_{\text {sample }}}{U F_{\text {positive control }}} \times 100
$$

\section{Cell adhesion}

The cell suspension $\left(4 \times 10^{5}\right)$ was seeded in samples of polyurethanes placed in the well bottom of a 96-well plate and incubated at $37{ }^{\circ} \mathrm{C}$ with $5 \% \mathrm{CO}_{2}$ for $3 \mathrm{~h}^{39}$. After the incubation time, nonadherent cells were removed and washing was performed three times using PBS. Finally, $50 \mu \mathrm{L}$ of resazurin solution ( $44 \mu \mathrm{M})$ was added and incubated for $4 \mathrm{~h}$. The fluorescent product resorufin was measured as explained above. Adhesion is expressed as the percentage of adherent cells to the total cells added to the well bottom. 
A morphological analysis using phalloidin and DAPI was performed. Polyurethanes with a suspension of SMCs $\left(5 \times 10^{3}\right)$ were cultured for $3 \mathrm{~h}$, washed with PBS, and then fixed for $20 \mathrm{~min}$ with formaldehyde $4 \% \mathrm{w} / \mathrm{v}$ at $20^{\circ} \mathrm{C}$. Subsequently, the samples were rinsed three times with PBS. Membrane permeabilisation was performed using Triton 100X in PBS for 15 min. After two more rinses with PBS, phalloidin (Alexa Flour ${ }^{\mathrm{TM}} 488$ phalloidin) at a 1:100 dilution in DPBS was added and incubated for $45 \mathrm{~min}$. The samples were then washed twice with PBS. The cell nuclei were stained for 5 min with Fluoroshield Mounting Medium and DAPI. The cell structure was observed using an Eclipse 80i optical microscope (Nikon, Tokyo, Japan) equipped with a Nikon Intensilight illuminator ${ }^{38}$. The images were analysed using ImageJ software version $1.45 \mathrm{k}$ (Bethesda, MD, USA).

\section{Leachate toxicity}

The samples were immersed in $1 \mathrm{~mL}$ of supplemented $\mathrm{SmBM}$ and incubated for 30 days at $37^{\circ} \mathrm{C}$ and $200 \mathrm{rpm}^{7}$. A cell suspension $(100 \mu \mathrm{L})$ with density $4 \times 10^{5}$ cell $/ \mathrm{mL}$ was seeded in 96 -well plates and cultured at $37{ }^{\circ} \mathrm{C}$ and $5 \% \mathrm{CO}_{2}$ for $24 \mathrm{~h}^{39}$. After incubation, the medium was removed and $100 \mu \mathrm{L}$ of the leachates was placed in the cells for $24 \mathrm{~h}$ at $37^{\circ} \mathrm{C}$ and $5 \% \mathrm{CO}_{2}$. Subsequently, $50 \mu \mathrm{L}$ of resazurin solution $(44 \mu \mathrm{M})$ was added and incubated for $4 \mathrm{~h}$ at $37^{\circ} \mathrm{C}$. The fluorescent product resorufin was measured as described previously.

\section{Statistical analysis}

All experiments were performed at least three independent times. Data were reported as mean \pm standard deviation and analysed by the one-way analysis of variance to determine the statistical significance. A p-value of less than 0.05 was considered significant. The Tukey multiple comparisons test was performed to determine the significant differences between pairs. Individual 
Student's t-tests were performed for pairwise comparisons when the hypothesis of similar standard deviations between samples was rejected.

\section{Acknowledgements}

The research and publication were supported by the Universidad de La Sabana (ING-205-2018) and the Minister of Science, Technology, and Innovation of the Republic of Colombia, MINCIENCAS (Contract number 80740-186-2019).

M. M-G would like to thank the Universidad de La Sabana for the scholarship for her master's studies. S. A-A would like to thank MINCIENCIAS for the doctoral training scholarship (Grant 727-2015). The authors are thankful to Professor Ericsson Coy Barrera and his staff at Nueva Granada Military University for the access to the Varioskan ${ }^{\mathrm{TM}}$ LUX multimode microplate reader.

J. A. S. acknowledges the financial support by MINECO through FIS2017-83295-P, MAT201571070-REDC, MAT2016-75586-C4-1/2/3-P and the Ramon y Cajal Fellowship (RYC-201517482).

CIBER-BBN is an initiative funded by the VI National R\&D\&I Plan 2008-2011, Iniciativa Ingenio 2010, Consolider Program. CIBER actions are financed by the Instituto de Salud Carlos III with assistance from the European Regional Development Fund.

\section{References}

1. J. Wu, C. Hu, Z. Tang, Q. Yu, X. Liu, and H. Chen: Tissue-engineered Vascular Grafts: Balance of the Four Major Requirements. Colloid Interface Sci. Commun. 23, 34 (2018).

2. E. Benrashid, C. C. McCoy, L. M. Youngwirth, J. Kim, R. J. Manson, J. C. Otto, and J. H. Lawson: Tissue 
engineered vascular grafts: Origins, development, and current strategies for clinical application. Methods 99, 13 (2016).

3. F. Xie, T. Zhang, P. Bryant, V. Kurusingal, J. M. Colwell, and B. Laycock: Degradation and stabilization of polyurethane elastomers. Prog. Polym. Sci. 90, 211 (2019).

4. S. Lyu and D. Untereker: Degradability of polymers for implantable biomedical devices. Int. J. Mol. Sci. 10(9), 4033 (2009).

5. H. Chen and G. S. Kassab: Microstructure-based biomechanics of coronary arteries in health and disease. $J$. Biomech. 49(12), 2548 (2016).

6. A. Agrawal, B. H. Lee, S. A. Irvine, J. An, R. Bhuthalingam, V. Singh, K. Y. Low, C. K. Chua, and S. S. Venkatraman: Smooth muscle cell alignment and phenotype control by melt spun polycaprolactone fibers for seeding of tissue engineered blood vessels. Int. J. Biomater. 2015 (2015).

7. H.-Y. Mi, X. Jing, B. S. Hagerty, G. Chen, A. Huang, and L.-S. Turng: Post-crosslinkable biodegradable thermoplastic polyurethanes: Synthesis, and thermal, mechanical, and degradation properties. Mater. Des. 127, 106 (2017).

8. I. Adipurnama, M. C. Yang, T. Ciach, and B. Butruk-Raszeja: Surface modification and endothelialization of polyurethane for vascular tissue engineering applications: A review. Biomater. Sci. 5(1), 22 (2017).

9. P. Krsko and M. Libera: Hydrogels Poly (ethylene glycol), or PEG, is used extensively in biomedical device. Mater. Today 8(12), 36 (2005).

10. J. Horakova, P. Mikes, A. Saman, V. Jencova, A. Klapstova, T. Svarcova, M. Ackermann, V. Novotny, T. Suchy, and D. Lukas: The effect of ethylene oxide sterilization on electrospun vascular grafts made from biodegradable polyesters. Mater. Sci. Eng. C 92, 132 (2018).

11. X. Jing, H. Y. Mi, M. R. Salick, T. Cordie, J. McNulty, X. F. Peng, and L. S. Turng: In vitro evaluations of electrospun nanofiber scaffolds composed of poly( $\varepsilon$-caprolactone) and polyethylenimine. J. Mater. Res. 30(11), 1808 (2015).

12. Z. Peng, P. Zhou, F. Zhang, and X. Peng: Preparation and Properties of Polyurethane Hydrogels Based on Hexamethylene Diisocyanate/Polycaprolactone-Polyethylene Glycol. J. Macromol. Sci. Part B Phys. 57(3), 187 (2018).

13. A. P. Tiwari, M. K. Joshi, J. Lee, B. Maharjan, S. W. Ko, C. H. Park, and C. S. Kim: Heterogeneous electrospun polycaprolactone/polyethylene glycol membranes with improved wettability, biocompatibility, and mineralization. Colloids Surfaces A Physicochem. Eng. Asp. 520, 105 (2017).

14. V. Kupka, L. Vojtova, Z. Fohlerova, and J. Jancar: Solvent free synthesis and structural evaluation of polyurethane films based on poly(Ethylene glycol) and poly(caprolactone). Express Polym. Lett. 10(6), 479 (2016).

15. C. Zhou, X. Zhou, and X. Su: Noncytotoxic polycaprolactone-polyethyleneglycol- $\epsilon-$ poly(l-lysine) triblock copolymer synthesized and self-assembled as an antibacterial drug carrier. RSC Adv. 7(63), 39718 (2017).

16. Y. Niu, K. C. Chen, T. He, W. Yu, S. Huang, and K. Xu: Scaffolds from block polyurethanes based on poly ( $\varepsilon$-caprolactone) (PCL) and poly(ethylene glycol) (PEG) for peripheral nerve regeneration. Biomaterials 35(14), 4266 (2014).

17. F. O. V. da Cunha, D. H. R. Melo, V. B. Veronese, and M. M. C. Forte: Study of castor oil polyurethane poly(methyl methacrylate) semi-interpenetrating polymer network (SIPN) reaction parameters using a $2^{3}$ factorial experimental design. Mater. Res. 7(4), 539 (2004).

18. A. P. Kotula, C. R. Snyder, and K. B. Migler: Determining conformational order and crystallinity in polycaprolactone via Raman spectroscopy. Polymer (Guildf). 117, 1 (2017).

19. A. Baranowska-Korczyc, A. Warowicka, M. Jasiurkowska-Delaporte, B. Grześkowiak, M. Jarek, B. M. Maciejewska, J. Jurga-Stopa, and S. Jurga: Antimicrobial electrospun poly( $\varepsilon$-caprolactone) scaffolds for gingival fibroblast growth. $R S C A d v$. 6(24), 19647 (2016).

20. A. Wesełucha-Birczyńska, M. Wwie,tek, E. Sołtysiak, P. Galiński, Płachta, K. Piekara, and M. Błazewicz: Raman spectroscopy and the material study of nanocomposite membranes from poly( $\varepsilon$-caprolactone) with 
biocompatibility testing in osteoblast-like cells. Analyst 140(7), 2311 (2015).

21. S. Arévalo-Alquichire, M. Morales-Gonzalez, K. Navas-Gómez, L. E. Diaz, J. A. Gómez-Tejedor, M. A. Serrano, and M. F. Valero: Influence of polyol/crosslinker blend composition on phase separation and thermo-mechanical properties of polyurethane thin films. Polymers (Basel). 12(3) (2020).

22. S. França de Sá, J. L. Ferreira, A. S. Matos, R. Macedo, and A. M. Ramos: A new insight into polyurethane foam deterioration - the use of Raman microscopy for the evaluation of long-term storage conditions. $J$. Raman Spectrosc. 47(12), 1494 (2016).

23. Y.-C. Chung, T. K. Cho, and B. C. Chun: Flexible Cross-Linking by Both Pentaerythritol and Polyethyleneglycol Spacer and its Impact on the Mechanical Properties and the Shape Memory Effects of Polyurethane. J. Appl. Polym. Sci. 112(5), 2800 (2009).

24. L. Chen, C. Yan, and Z. Zheng: Functional polymer surfaces for controlling cell behaviors. Mater. Today 21(1), 38 (2018).

25. Y. Yuan and T. R. Lee: in Bracco G., Holst B. Surf. Sci. Tech. (Springer, Berlin, Heidelberg, 2013), pp. 334.

26. S. Asadpour, J. Ai, P. Davoudi, M. Ghorbani, M. Jalali Monfared, and H. Ghanbari: In vitro physical and biological characterization of biodegradable elastic polyurethane containing ferulic acid for small-caliber vascular grafts. Biomed. Mater. 13(3) (2018).

27. X. Liu, Y. Xia, L. Liu, D. Zhang, and Z. Hou: Synthesis of a novel biomedical poly(ester urethane) based on aliphatic uniform-size diisocyanate and the blood compatibility of PEG-grafted surfaces. J. Biomater. Appl. 32(10), 1329 (2018).

28. Z. Hou, J. Xu, J. Teng, Q. Jia, and X. Wang: Facile preparation of medical segmented poly(ester-urethane) containing uniformly sized hard segments and phosphorylcholine groups for improved hemocompatibility. Mater. Sci. Eng. C 109(September 2019), 110571 (2020).

29. V. H. Huxley and S. S. Kemp: Sex-Specific Characteristics of the Microcirculation (2018).

30. P. H. Blit, K. G. Battiston, M. Yang, J. P. Santerre, and K. A. Woodhouse: Electrospun elastin-like polypeptide enriched polyurethanes and their interactions with vascular smooth muscle cells. Acta Biomater. 8(7), 2493 (2012).

31. F. Wolf, F. Vogt, T. Schmitz-Rode, S. Jockenhoevel, and P. Mela: Bioengineered vascular constructs as living models for in vitro cardiovascular research. Drug Discov. Today 21(9), 1446 (2016).

32. A. Tijore, J. M. Behr, S. A. Irvine, V. Baisane, and S. Venkatraman: Bioprinted gelatin hydrogel platform promotes smooth muscle cell contractile phenotype maintenance. Biomed. Microdevices 20(2) (2018).

33. H.-I. Chang and Y. Wang: in Regen. Med. Tissue Eng. - Cells Biomater. (2012), pp. 569-588.

34. J. Guan, M. S. Sacks, E. J. Beckman, and W. R. Wagner: Biodegradable poly(ether ester urethane)urea elastomers based on poly(ether ester) triblock copolymers and putrescine: Synthesis, characterization and cytocompatibility. Biomaterials 25(1), 85 (2004).

35. X. Le, G. Eddy, J. Poinern, N. Ali, C. M. Berry, and D. Fawcett: Engineering a Biocompatible Scaffold with Either Micrometre or Nanometre Scale Surface Topography for Promoting Protein Adsorption and Cellular Response. Int. J. Biomater. 2013 (2013).

36. T. Zehnder, T. Freund, M. Demir, R. Detsch, and A. R. Boccaccini: Fabrication of cell-loaded two-phase 3D constructs for tissue engineering. Materials (Basel). 9(11) (2016).

37. M. E. Hoque, W. Y. San, F. Wei, S. Li, M.-H. Huang, M. Vert, and D. W. Hutmacher: Processing of Polycaprolactone and Polycaprolactone-Based Copolymers into 3D Scaffolds, and Their Cellular Responses. Tissue Eng. Part A 15(10), 3013 (2009).

38. Y. L. Uscátegui, L. E. Díaz, J. A. Gómez-Tejedor, A. Vallés-Lluch, G. Vilariño-Feltrer, M. A. Serrano, and M. F. Valero: Candidate polyurethanes based on castor oil (ricinus communis), with polycaprolactone diol and chitosan additions, for use in biomedical applications. Molecules 24(2), 237 (2019).

39. Y. L. Uscátegui, S. J. Arévalo-Alquichire, J. A. Gómez-Tejedor, A. Vallés-Lluch, L. E. Díaz, and M. F. Valero: Polyurethane-based bioadhesive synthesized from polyols derived from castor oil (Ricinus 
communis) and low concentration of chitosan. J. Mater. Res. 32(19), 3699 (2017). 